\title{
Multiple Hispanic
}

National Cancer Institute

\section{Source}

National Cancer Institute. Multiple Hispanic. NCI Thesaurus. Code C67111.

A person living in the United States of Mexican, Puerto Rican, Cuban, Central or South

American, or other Spanish culture or origin. The concept does not include Brazilian Americans or Portuguese Americans. 